\title{
Expression Profile of Circulatory Adiponectin and Plasma Variables in Broilers
}

http://dx.doi.org/10.1590/1806-9061-2020-1302

mAuthor(s)

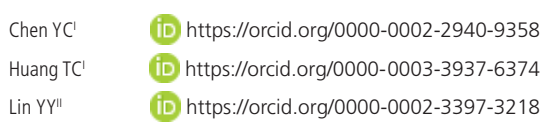

Department of Animal Science and Biotechnology Tunghai University, No. 1727, Sec. 4, Taiwan Boulevard, Xitun District, Taichung 407, Taiwan.

Department of Animal Science and Technology, National Taiwan University, No. 50, Lane 155, Sec. 3, Keelung Rd, Taipei, 106, Taiwan.

\section{-Mail Address}

Corresponding author e-mail address Yuan-Yu Lin

National Taiwan University, No. 50, Lane 155, Sec. 3, Keelung Road, Da'an District, Taipei City 106, Taiwan

Phone: 8860233664151

Email: yylin@ntu.edu.tw

\section{EKeywords}

Adiponectin, high-molecular weight adiponectin, chicken.

\section{ABSTRACT}

Adipokines serve as a human clinical biomarker and they regulate mammalian metabolic functions. Research on adipokine regulation of metabolic function in avian species is limited. The current study is to investigate the profile of plasma adiponectin and several biochemical variables in broilers, to establish the pattern of development.

A total of one hundred and fifty-two 1-day-old Arbor Acres broilers were separated by different gender and homogenously divided into 2 groups (male and female), with 6 replicate pens and at least 12 chickens per pen. The data for body weight, plasma variables, and feed consumption were collected at days 3, 7, 14, 21, 28 and 35 after hatching. Plasma monomer adiponectin, high-molecular weight (HMW) adiponectin and biochemical variables, including triacylglycerol, total cholesterol, glucose, high-density lipoprotein and low-density lipoprotein were quantified. Monomer adiponectin was highly correlated with age in a negative fashion and with HMW adiponectin in a positive fashion in both genders in broilers. Moreover, body weight was highly correlated with monomer adiponectin in a negative fashion and positively correlated with HMW adiponectin in growing chickens.

It was concluded that monomer adiponectin and HMW adiponectin have highly correlation with age, body weight and biochemical variables in chickens and further investigation is needed for physiological or nutritional functions.

\section{INTRODUCTION}

In the late $20^{\text {th }}$ century, many adipokines and their physiological functions were discovered (Lago et al., 2007). White adipose tissue is the main energy store of the body, but is also a source of cytokines that modulate metabolic and immune functions. Although many adipokines are well known in mammals, information about them is lacking in nonmammalian species. Adiponectin is a cytokine secreted from adipocytes consisting of a single peptide with a collagen-like domain and a globular domain (Okamoto et al., 2006). Exogenous administration of adiponectin to mammals decreases blood biochemical variables, such as glucose, free fatty acids and triglycerides; increases muscular fatty acid oxidation and induces weight loss (Fruebis et al., 2001). Reduced adiponectin levels and actions are associated with obesity and type 2 diabetes. Increasing adiponectin signaling and actions reduces diet-induced obesity, inflammation, insulin resistance, cardiovascular diseases, and type 2 diabetes (Turer \& Scherer, 2012; Li et al., 2012). This suggests a promising approach for the treatment of metabolic dysregulation diseases.

The chicken adiponectin cDNA is composed of 735 nucleotides and has $65 \%$ to $68 \%$ homology with mammals (Maddineni et al., 2005; 
Yuan et al., 2006). Adiponectin receptors in chicken have high homology with mammals (from $76 \%$ to 83\%) (Ramachandran et al., 2007). In addition to the chickens, turkeys and geese also express adiponectin and adiponectin receptors (Caoetal., 2015; Diotetal., 2015). There is basic information on the genome of poultry (Burt, 2006). However, the physiological function of adiponectin is still unclear. It is important to explore the function or correlation among adiponectin, chicken manifestations and biochemical values. Our hypothesis is that chicken adiponectin or HMW adiponectin have a correlation with biochemical variables and physiological manifestations, such as body weight and ages. The goal of the current study is to investigate the profiles of plasma adiponectin and its relationship to plasma biochemical variables in growing chickens.

\section{MATERIALS AND METHODS}

\section{Animals, treatments, diets and sampling}

All chicken experiments were exerted in accordance with animal welfare guidelines and approved by the Institutional Animal Care and Use Committee at Tunghai University (THU, approval no. 106-15).

A total of one hundred and fifty-two 1-day-old Arbor Acres broilers were separated by different gender and homogenously divided into 2 groups (male and female), with 6 replicate pens and at least 12 chickens per pen. The feeding strategy was adapted from the Broiler Management Manual (Arbor Acres, 2012). At each stage (days 3, 7, 14, 21, 28 and 35 after hatching), twelve chickens (both genders) were randomly selected from each pen ( 2 chickens per pen) and weighed at feeding. The composition and nutrient levels of diets at different stages are presented in table 1 . At each stage chickens were sacrificed and plasma was collected for measurement of monomer adiponectin, HMW adiponectin, glucose, total cholesterol, triacylglycerol, high-density lipoprotein and low-density lipoprotein. Peripheral tissues including thigh muscle, abdominal fat and liver were harvested to measure mRNA expression of adiponectin and adiponectin receptor by real-time PCR analysis. Total RNA was extracted and converted to CDNA which procedure was modified by Lin et al. (2013).

\section{Measurement of plasma adiponectin pro- files and biochemical variables}

Blood was drawn from the brachial wing using EDTA as anticoagulant. Plasma samples were prepared by centrifugation $\left(2,000 \times \mathrm{g}\right.$ for $\left.15 \mathrm{~min}, 4^{\circ} \mathrm{C}\right)$. The
Table 1 - Diet composition and calculated nutrition levels.

\begin{tabular}{lcc}
\hline Ingredient (\%) & Diet (0-21 days) & Diet (22-35 days) \\
\hline Yellow corn & 51.22 & 58.80 \\
\hline Soybean meal & 40.00 & 33.00 \\
\hline Soybean oil & 4.5 & 4.49 \\
\hline Choline & 0.15 & 0.15 \\
\hline BHT & 0.02 & 0.02 \\
\hline Dicalcium phosphate & 1.65 & 1.21 \\
\hline Calcium carbonate & 1.63 & 1.60 \\
\hline DL-methionine & 0.18 & 0.08 \\
NaCl & 0.35 & 0.35 \\
\hline Vitamin premix & 0.15 & 0.15 \\
Mineral premix & 0.15 & 0.15 \\
Total & 100 & 100 \\
Calculated value & & \\
ME (kcal/kg) & 3340.31 & 3384.34 \\
Crude protein (\%) & 23.16 & 20.41 \\
\hline Total lipid (\%) & 6.99 & 7.16 \\
Lysine (\%) & 1.33 & 1.14 \\
\hline Methionine (\%) & 0.60 & 0.39 \\
\hline Methionine+Cysteine (\%) & 0.95 & 0.78 \\
Calcium (\%) & 1.00 & 0.91 \\
Nonphytate phosphorus (\%) & 0.45 & $0 . .36$ \\
\hline
\end{tabular}

Provided per kg of diet (vitamin): vitamin A, 10,000 IU; vitamin $\mathrm{D}_{3^{\prime}} 2,000 \mathrm{IU}$; vitamin E, $15 \mathrm{mg}$; vitamin $\mathrm{K}$, $4 \mathrm{mg}$; thiamine, $2 \mathrm{mg}$; riboflavin, $6 \mathrm{mg}$; pyridoxine, $4 \mathrm{mg}$; vitamin $\mathrm{B}_{12}, 0.02 \mathrm{mg}$; pantothenate, $12 \mathrm{mg}$; niacin, $40 \mathrm{mg}$; folate, $1 \mathrm{mg}$; biotin, $0.02 \mathrm{mg}$.

2 Provided per kg of diet (mineral): Zn, 90 mg; Mn, 100 mg; I, 1 mg; Cu, 15 mg; Fe, 90 mg; l, 200 mg; Se, 0.15 mg; Co, 0.25 mg.

supernatant fraction was collected and stored at - $80{ }^{\circ} \mathrm{C}$ for ELISA analysis. Plasma samples were diluted to appropriate concentrations with saline, and levels of glucose (\#3150, Fujifilm, Kanagawa, Japan) triacylglycerol (TG) (\#1650, Fujifilm, Kanagawa, Japan), total cholesterol (CHOL) (\#1450, Fujifilm, Kanagawa, Japan), high-density lipoprotein (\#2650, Fujifilm, Kanagawa, Japan) and low-density lipoprotein (\#3450, Denka Seiken, Niigata, Japan) were measured by biochemistry automatic analyzer (FUJ DRI-CHEM NX 500i, Fujifilm Co., Japan). Chicken monomer adiponectin (ADP) and HMW adiponectin were analyzed by commercial ELISA kits according to manufacturer's directions (Ch ADP, E12A0125, and; Ch MADP, E12M0038, Shanghai, BlueGene Biotech). The intra and inter assay coefficient of variability for the adiponectin kits were smaller than $10 \%$.

\section{Statistical analysis}

Data were analyzed using Statistical Analysis Systems software (Version 8.2, SAS Institute, Cary, NC, USA, 2001). Correlation between monomer adiponectin, HMW adiponectin with days of age on both gender was analyzed by Pearson's method. Correlation between monomer adiponectin, HMW adiponectin and biochemical variables were analyzed 
by Spearman's correlation coefficients. $p \leq 0.05\left({ }^{*}\right)$, $\left.p \leq 0.01^{* *}\right)$ or $p \leq 0.001 \quad(* * *)$ were considered significant. Data of age with an analysis of covariance (ANCOVA) are presented as mean \pm SEM. ANCOVA analysis were used to determine whether gender and body weight have an effect on each variable. Table 2, table 3 and figure 1 were assessed by a one-way ANOVA procedure. The Tukey's multiple comparison test was used to evaluate differences among means. A significant difference was considered at $p \leq 0.05$.

\section{RESULTS}

\section{The expression profile of plasma adipo- nectin in growing broilers}

Body and liver weight varied with age, as expected (Table 2). Liver weight increased with age and the ratio of liver weight (LW)/body weight (BW) decreased with age (Table 2).
The plasma level of monomer adiponectin ranged from 2 to $8 \mu \mathrm{g} / \mathrm{mL}$ and $\mathrm{HMW}$ adiponectin ranged from 1.5 to $13 \mu \mathrm{g} / \mathrm{mL}$ in growing broilers (Figure 1). The concentration of monomer adiponectin gradually decreased with age, whereas the level of HMW adiponectin increased with age. It should be noted that genders showed that there was no significant effect of blood variables by ANOVA analysis in this trial (data not shown). (a)

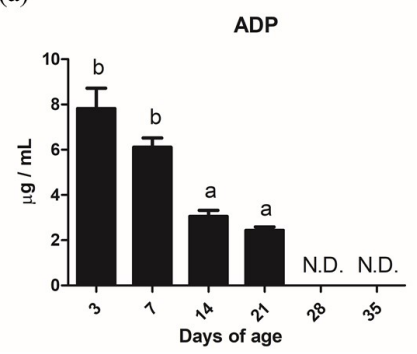

(b)

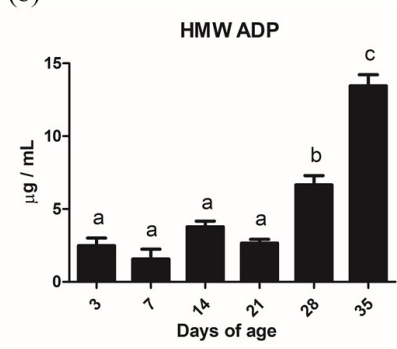

Figure 1 - Chicken plasma levels of adiponectin (a) and HMW ADP (b) in broilers. Data indicated as mean with S.E. represented by vertical bars. Different letters indicate statistical significance. N.D. $=$ non-detectable. $(n=25-27)$.

Table 2 - Body weight, liver weight and ratio of LW/BW in various with age.

\begin{tabular}{|c|c|c|c|c|c|c|}
\hline \multicolumn{7}{|l|}{ Male } \\
\hline \multirow{2}{*}{$\begin{array}{l}\text { Days of age } \\
\mathrm{N}\end{array}$} & 3 & 7 & 14 & 21 & 28 & 35 \\
\hline & 13 & 12 & 12 & 12 & 12 & 12 \\
\hline Body weight (g) & $57.26 \pm 7.54^{a}$ & $135.68 \pm 20.69 a$ & $400.17 \pm 54.64 b$ & $746.50 \pm 79.46 c$ & $1220.70 \pm 91.60 d$ & $1838.71 \pm 208.59 e$ \\
\hline Liver weight (g) & $2.65 \pm 0.48^{a}$ & $6.21 \pm 1.40^{a}$ & $12.06 \pm 1.50^{\mathrm{b}}$ & $19.50 \pm 2.46 \mathrm{c}$ & $33.98 \pm 5.12^{d}$ & $49.12 \pm 2.56 \mathrm{e}$ \\
\hline Ratio (LW/BW) & $0.046 \pm 0.006^{a}$ & $0.046 \pm 0.009 a$ & $0.030 \pm 0.004^{b}$ & $0.026 \pm 0.002^{b}$ & $0.029 \pm 0.004^{b}$ & $0.027 \pm 0.002^{b}$ \\
\hline \multicolumn{7}{|l|}{ Female } \\
\hline \multirow{2}{*}{$\begin{array}{l}\text { Days of age } \\
\mathrm{N}\end{array}$} & 3 & 7 & 14 & 21 & 28 & 35 \\
\hline & 14 & 13 & 13 & 13 & 13 & 13 \\
\hline Body weight(g) & $59.74 \pm 6.15^{a}$ & $149.86 \pm 20.77 a$ & $369.77 \pm 61.51^{b}$ & $758.00 \pm 99.98 c$ & $1124.77 \pm 142.54^{d}$ & $1674.67 \pm 168.95^{e}$ \\
\hline Liver weight(g) & $3.03 \pm 0.38 a$ & $6.17 \pm 1.19 a$ & $11.50 \pm 1.87 b$ & $18.68 \pm 4.65^{c}$ & $36.59 \pm 5.16^{d}$ & $47.86 \pm 8.13 \mathrm{e}$ \\
\hline Ratio (LW/BW) & $0.050 \pm 0.006 a$ & $0.042 \pm 0.008^{b}$ & $0.031 \pm 0.003^{c}$ & $0.026 \pm 0.005 c$ & $0.033 \pm 0.004 \mathrm{~cd}$ & $0.029 \pm 0.004 \mathrm{~cd}$ \\
\hline
\end{tabular}

Data are expressed as mean \pm SE. Different letters indicate statistical significance.

\section{The correlation of plasma adiponectin and biochemical parameters}

Table 3 indicated the plasma biochemical values for TG, TCHO, GLU, HDL and LDL at different ages.
Plasma TG decreased with age and then increased at older ages. Plasma TCHO was only elevated at day 3. Plasma glucose was constantly stable. Plasma HDL was elevated at day 3 and again at day 21 and 35 . Plasma LDL was elevated at day 3, 28 and 35.

Table 3 - The level of blood biochemical values at different days of age.

\begin{tabular}{lcccccc}
\hline \multirow{2}{*}{ Days of age } & \multicolumn{5}{c}{ Blood biochemical values, $\mathrm{mg} / \mathrm{dL}$} \\
\cline { 2 - 7 } & $\mathrm{N}$ & $\mathrm{TG}^{1}$ & $\mathrm{TCHO}^{2}$ & $\mathrm{GLU}^{3}$ & $\mathrm{HDL}^{4}$ & $\mathrm{LDL}^{5}$ \\
\hline 3 & 27 & $156.783 \pm 17.6^{\mathrm{a}}$ & $224.870 \pm 11.3^{\mathrm{a}}$ & $268.739 \pm 10.2^{\mathrm{a}}$ & $68.087 \pm 1.3^{\mathrm{abc}}$ & $87.000 \pm 3.0^{\mathrm{a}}$ \\
7 & 25 & $108.238 \pm 15.7^{\mathrm{a}}$ & $116.810 \pm 3.9^{\mathrm{b}}$ & $263.238 \pm 12.5^{\mathrm{a}}$ & $65.857 \pm 1.5^{\mathrm{ab}}$ & $63.095 \pm 2.2^{\mathrm{b}}$ \\
14 & 25 & $73.958 \pm 8.0^{\mathrm{b}}$ & $125.208 \pm 4.3^{\mathrm{b}}$ & $296.250 \pm 11.3^{\mathrm{a}}$ & $64.667 \pm 1.3^{\mathrm{a}}$ & $56.750 \pm 1.2^{\mathrm{bc}}$ \\
21 & 25 & $59.833 \pm 7.0^{\mathrm{b}}$ & $123.625 \pm 4.5^{\mathrm{b}}$ & $266.375 \pm 8.2^{\mathrm{a}}$ & $74.125 \pm 2.3^{\mathrm{b}}$ & $50.875 \pm 1.2^{\mathrm{c}}$ \\
28 & 25 & $143.091 \pm 18.9^{\mathrm{a}}$ & $127.182 \pm 4.4^{\mathrm{b}}$ & $292.727 \pm 4.2^{\mathrm{a}}$ & $62.682 \pm 2.4^{\mathrm{ac}}$ & $85.773 \pm 1.4^{\mathrm{a}}$ \\
35 & 25 & $164.111 \pm 16.8^{\mathrm{a}}$ & $133.05 \pm 6.6^{\mathrm{b}}$ & $291.778 \pm 5.6^{\mathrm{a}}$ & $67.944 \pm 2.2^{\mathrm{abc}}$ & $87.778 \pm 1.5^{\mathrm{a}}$ \\
\hline
\end{tabular}

Values are given as mean \pm standard error (SE). ${ }^{\top} \mathrm{TG}$, triglycerides; ${ }^{2} \mathrm{TCHO}$, total cholesterol; ${ }^{3} \mathrm{GLU}$, glucose; ${ }^{4} \mathrm{HDL}$, high-density lipoprotein; ${ }^{5} \mathrm{LDL}$, low-density lipoprotein. Data are expressed as mean $\pm \mathrm{SE}$. Different letters indicate statistical significance. 
Body weight was highly negatively correlated with monomer adiponectin ( $r$ value $=-0.8291$ ) and positively correlated with HMW adiponectin ( $r$ value $=0.7482$ ) (Table 4).

The ratio of liver weight to body weight (LW/BW) was positively correlated with monomer adiponectin $(r=0.3304)$ and negatively correlated HMW adiponectin $(r=-0.3202)$ (Table 4). Plasma TG ( $r$ value $=-0.3834)$,
GLU ( $r$ value $=-0.3303$ ) and LDL ( $r$ value $=-0.6138$ ) were negatively correlated with monomer adiponectin. In contrast, HMW adiponectin was positively correlated with TG $(r=0.2869), \quad G L U \quad(r=0.2481)$ and LDL $(r=0.5180)$ (Table 4).

ANCOVA analysis were used to determine whether gender and body weight have an effect on each variable. The data of ANCOVA are shown in supplemental table 1.

Table 4 - The correlation of ADP, HMW ADP and blood biochemical values.

\begin{tabular}{|c|c|c|c|c|c|c|c|c|c|}
\hline & LW & TG & $\mathrm{TCHO}$ & GLU & $\mathrm{HDL}$ & LDL & ADP & HMW ADP & ratio \\
\hline BW & $0.9759 * *$ & 0.3001 ** & $0.2012^{*}$ & $0.3212 * *$ & 0.1361 & $0.4884 * *$ & $-0.8291 * *$ & $0.7482 * *$ & $-0.5521 * *$ \\
\hline LW & & $0.3519 * *$ & $0.1966^{*}$ & $0.3564^{* *}$ & 0.0988 & $0.5088^{* *}$ & $-0.8439 * *$ & $0.7405^{* *}$ & $-0.4253^{* *}$ \\
\hline TG & & & $0.2420 * *$ & 0.4674 ** & 0.0166 & $0.6233^{* *}$ & $-0.3834 * *$ & $0.2869 * *$ & 0.1697 \\
\hline $\mathrm{TCHO}$ & & & & $0.2806^{* *}$ & $0.2080^{*}$ & 0.1809 & -0.1397 & 0.0804 & -0.0913 \\
\hline GLU & & & & & 0.0027 & 0.3041 * * & $-0.3303^{* *}$ & $0.2481 * *$ & -0.04290 \\
\hline $\mathrm{HDL}$ & & & & & & 0.0490 & 0.0636 & -0.0044 & $-0.2635^{\star *}$ \\
\hline LDL & & & & & & & $-0.6138 * *$ & $0.5180 * *$ & 0.1341 \\
\hline ADP & & & & & & & & $-0.6777 * *$ & $0.3304^{* *}$ \\
\hline HMW ADP & & & & & & & & & $-0.3202 * *$ \\
\hline
\end{tabular}

BW, body weight; LW, liver weight; TG, triglycerides; TCHO, total cholesterol; GLU, glucose; HDL, high-density lipoprotein; LDL, low-density lipoprotein; ADP, adiponectin; HMW ADP, high-molecular weight adiponectin; ratio, LW/BW.

${ }^{*} p \leq .05 ;{ }^{* *} p \leq .01$

\section{DISCUSSION}

Adiponectin functions have been elucidated for two decades in rodents and mammalian species (Scherer et al., 1995). The characteristics of adiponectin and its signaling are also defined, but these features are still unclear in avian species. A study on profiles of adiponectin and plasma variables in growing broilers has not been reported before. We hypothesized that chicken monomer adiponectin or HMW adiponectin have a correlation with biochemical variables and physiological manifestations, such as body weight and ages. And such correlation has been confirmed by our results. These findings can provide a view of the regulation of the basic physiological functions in chicken. The level of circulatory adiponectin is similar to mammalian species (from 1.5 to $13 \mu \mathrm{g}$ / $\mathrm{mL}$ in broilers), and the high molecular weight forms of adiponectin were dominant; consistent with a previous study (Chou et al., 2014; Hendricks et al., 2009). Since adiponectin is secreted by adipose tissue (Okamoto et al., 2006), as the age of the animal increases the amount of fat increases which indicate that adiponectin may have strong correlation with fat mass (Baéza and Bihan-Duval, 2013; Guo et al., 2011). Regarding the fat mass, we did not collect all the fat tissue in the chicken. And according to previous literature, the fat mass increased with age (Baéza and Bihan-Duval, 2013; Guo et al., 2011). Interestingly, we found that the monomeric adiponectin decreased, while the oligomeric HMW form adiponectin increased with age. The fat disulfide-bond-A oxidoreductase-like protein (DsbA-L) is a regulator involved in adiponectin multimerization. Our previous study found that the mRNA expression of DsbA-L increased by high-fat diet feeding which means a larger amount of adipose tissue may have higher HMW adiponectin production (Chen et al., 2018). And young birds are existing monomeric adiponectin majority, which may also impact by DsbA-L. In the current study, we did not observe obvious abdominal fat deposition in chicks within seven days of age which may indicate that the secretion of monomeric adiponectin may be secreted by other adipose tissue, such as jugular subcutaneous fat, femoral subcutaneous fat, heart coronary adipose tissue or gastric adipose tissue. However, the secretory profile of monomeric adiponectin needs to be further analyzed to clarify.

Adiponectin receptors in chicken are expressed in various tissues, such as adipose tissue, skeletal muscle, liver, diencephalon, and reproductive glands (OconGrove et al., 2008; Ramachandran et al., 2013). Chicken Adiponectin receptor 1 is mainly expressed in skeletal muscle, fat and diencephalon; whereas, Adiponectin receptor 2 is predominantly found in adipose tissue. In the current study, we have evaluated the expression profile of adiponectin receptor 1 and 2. However, we did not find the specific pattern of 
thigh muscle, abdominal fat and liver tissue (data not shown). In addition to the chickens, other poultry species such as turkey and goose also have adiponectin and adiponectin receptors (Cao et al., 2015; Diot et al., 2015). Adiponectin is expressed in varying degrees at different egg production stages of turkeys. At the early stage of spawning, the expression levels of adiponectin and its receptors were relatively higher; the concentration of circulating adiponectin decreased significantly as the egg production decreased during the late egg production stage (Diot et al., 2015).

Broiler chickens grow fast with high feed efficiency, but an adverse effect is obesity with excessive fat accumulation accompanied by poor energy efficiency and consequent increased costs; Laying hens are prone to develop hemorrhagic fatty liver of the peak of egg production, similar to human fatty liver symptoms. Fat accumulation in the liver is a serious problem, causing a decrease in egg production (Tsai et al., 2017). Previous researches use various nutrients to regulate chicken performance and promote energy efficiency. The level of vitamin $E$ in blood is negatively correlated with obesity (Laight et al., 1999; Mayer-Davis et al., 2002). Both vitamin $\mathrm{E}$ and adiponectin function to ameliorate insulin resistance (Costacou et al., 2008; Lara-Castro et al., 2007). Treatment with glycine enhances expression of adiponectin in 3T3-L1 cells ( Garcia-Macedo et al., 2008). In mammals, adiponectin is regarded as an anti-inflammatory cytokine and improves type 2 diabetes, obesity and atherosclerosis (Oh et al., 2007). Glycine is also an important antioxidant and improves adiponectin expression (Tataranni and Ortega, 2005). There are few reports on the effects of nutrients or feeding strategy on adiponectin signaling in chickens. Regardless, we speculate that there are nutrients that can regulate adiponectin signaling and improve the health of chickens. Restricted feeding (feeding every other day) cause broiler weight loss and a decrease in abdominal fat and adiponectin levels, but these effects are not maintained at 49 days of age (Tahmoorespur et al., 2010). Moreover, a low protein diet (16.3\%) increases the expression of adiponectin in 32-day-old broilers, but not in broilers at 49 days of age; raising the energy supply in the diet also increases the expression of adiponectin in abdominal fat (Tahmoorespur et al., 2010). The mRNA expression of adiponectin is decreased in fat, liver and brain tissues after 48 hours fasting in broilers (Maddineni et al., 2005). In this study, we analyzed the profile of mRNA expression in peripheral tissues, including fat, liver and muscle tissues but found no specific pattern for adiponectin related signaling (data not shown).
In general, chicken adiponectin and its receptors have a high degree of homology for DNA and amino acid sequences with mammals, but there are many differences in physiological function (Ramachandran et al., 2007; Chen et al., 2018). The current study supplies values for adiponectin at various stages of growing broilers and further analyzed plasma biochemical variables and their correlation with plasma adiponectin.

\section{ACKNOWLEDGEMENTS}

The authors express gratitude to the laboratory members for their help and input during this study. Authors would like to thank Dr. Harry John Mersmann for editing the manuscript. Funds supporting for this study were provided by the Ministry of Science and Technology, Taiwan (project no. 106-2313-B-029003-MY2, project no. no.108-2313-B-002-062 and 109-2321-B-003-001) and National Taiwan University (project no. NTU-JP-109L7244 and no. 110L7225).

\section{CONFLICT OF INTEREST}

The authors declare that they have no conflict of interest.

\section{REFERENCES}

Arbor Acres. Broiler management manual. Taipei City: Arbor Acres Taiwan Co.; 2012.

Burt DW. The Chicken genome. Genome Dynamics 2006;2:123-137.

Baéza E, Bihan-Duval EL. Chicken lines divergent for low or high abdominal fat deposition: a relevant model to study the regulation of energy metabolism. Animal 2013;7:965-973.

Cao Z, Li J, Lina L, Li X, Liu M, Gao M, et al. Molecular cloning and expression analysis of adiponectin and its receptors (AdipoR1 and AdipoR2) in the hypothalamus of the Huoyan goose during different stages of the egglaying cycle. Reproductive Biology and Endocrinology 2015;13:87.

Chen CY, Chen YJ, Ding ST, Lin YY. Expression profile of adiponectin and adiponectin receptors in high-fat diet feeding chickens. Journal of Animal Physiology and Animal Nutrition 2018;102:1585-1592.

Chou IP, Lin YY, Ding ST, Chen CY. Adiponectin receptor 1 enhances fatty acid metabolism and cell survial in palmitate-treated HepG2 cells through the PI3K/AKT pathway. European Journal of Nutrition 2014;53:907-917.

Costacou T, Ma B, King I, Mayer-Davis E. Plasma and dietary vitamin e in relation to insulin secretion and sensitivity. Diabetes, Obesity and Metabolism 2008;10:223-228.

Diot M, Reverchon M, Rame C, Froment P, Brillard J, Briere S, et al. Expression of adiponectin, chemerin and visfatin in plasma and different tissues during a laying season in turkeys. Reproductive Biology and Endocrinology 2015;13:81. 
Fruebis J, Tsao TS, Javorschi S, Ebbets-Reed D, Erickson MR, Yen FT, et al. Proteolytic cleavage product of 30-kDa adipocyte complement-related protein increases fatty acid oxidation in muscle and causes weight loss in mice. Proceedings of the National Academy Sciences of the United States of America 2001;98:2005-2010.

Garcia-Macedo R, Sanchez-Muroz F, Almanza-Perez JC, Duran-Reyes G, Alarcon-Aguilar F, Cruz M. Glycine increases mRNA adiponectin and diminishes pro-inflammatory adipokines expression in 3T3-L1 cells. European Journal of Pharmacology 2008;587:317-321.

Guo L, Sun B, Shang Z, Leng L, Wang Y, Wang N, et al. Comparison of adipose tissue cellularity in chicken lines divergently selected for fatness. Poultry Science 2001;90:2024-2034.

Hendricks 3rd GL, Hadley JA, Krzysik-Walker SM, Prabhu KS, VasilatosYounken R, Ramachandran R. Unique profile of chicken adiponectin, a predominantly heavy molecular weight multimer, and relationship to visceral adiposity. Endocrinology 2009;150:3092-3100.

Lago F, Dieguez C, Gómez-Reino J, Gualillo O. Adipokines as emerging mediators of immune response and inflammation. Nature Clinical Practice Rheumatology 2007;3:716-724.

Laight D, Desai K, Gopaul N, Anggard E, Carrier M. F2-isoprostane evidence of oxidant stress in the insulin resistant, obese zucker rat: effects of vitamin E. European Journal of Pharmacology 1999;377:89-92.

Lara-Castro C, Fu Y, Chung B, Garvey W. Adiponectin and the metabolic syndrome: mechanisms mediating risk for metabolic and cardiovascular disease. Current Opinion in Lipidology 2007;18:263-270.

Li FY, Lam HS, Xu A. Therapeutic perspectives for adiponectin: an update. Current Medicinal Chemistry 2012;19:5513-5523

Lin $Y Y$, Chen $C Y$, Lin $Y$, Chiu YP, Chen CC, Liu BH, et al. Modulation of glucose and lipid metabolism by porcine adiponectin receptor 1-transgenic mesenchymal stromal cells in diet-induced obese mice. Cytotherapy 2013;15:971-978.

Maddineni S, Metzger S, Ocón-Grove O, Hendricks 3rd G, Ramachandran $\mathrm{R}$. Adiponectin gene is expressed in multiple tissues in the chicken: food deprivation influences adiponectin messenger ribonucleic acid expression. Endocrinology 2005;146:4250-4256.

Mayer-Davis E, Costacou T, King I, Zaccaro D, Bell R. Plasma and dietary vitamin $E$ in relation to incidence of type 2 diabetes. Diabetes Care 2002;25:2172
Ocón-Grove OM, Krzysik-Walker SM, Maddineni SR, Hendricks 3rd GL, Ramachandran R. Adiponectin and its receptors are expressed in the chicken testis: influence of sexual maturation on testicular ADIPOR1 and ADIPOR2 mRNA abundance. Reproduction 2008;136:627-638.

Ramachandran R, Ocón-Grove OM, Metzger SL. Molecular cloning and tissue expression of chicken AdipoR1 and AdipoR2 complementary deoxyribonucleic acids. Domestic Animal Endocrinology 2007;33:1931.

Ramachandran R, Maddineni S, Ocón-Grove O, Hendricks 3rd G, VasilatosYounken R, Hadley JA. Expression of adiponectin and its receptors in avian species. General and Comparative Endocrinology 2013;190:8895.

Scherer PE, Williams S, Fogliano M, Baldini G, Lodish HF. A novel serum protein similar to $\mathrm{C} 1 \mathrm{q}$, produced exclusive in adipocytes. The Journal of Biological Chemistry 1995;270:26746-26749.

Tahmoorespur M, Ghazanfari S, Nobari K. Evaluation of adiponectin gene expression in the abdominal adipose tissue of broiler chickens: feed restriction, dietary energy, and protein influences adiponectin messenger ribonucleic acid expression. Poultry Science 2010;89:20922100

Tataranni P, Ortega E. A burning question: does an adipokine-induced activation of the immune system mediate the effect of overnutrition on type 2 diabetes? Diabetes 2005;54:917-927.

Tsai MT, Chen YJ, Chen CY, Tsai MH, Han CL, Chen YJ, et al. Identification of potential plasma biomarkers for nonalcoholic fatty liver disease by integrating transcriptomics and proteomics in laying hens. The Journal Nutrition 2017;147:293-303

Turer AT, Scherer PE. Adiponectin: mechanistic insights and clinical implications. Diabetologia 2012;55:2319-2326.

Oh D, Ciaraldi T, Henry R. Adiponectin in health and disease. Diabetes Obesity and Metabolism 2007;9:282-289.

Okamoto Y, Kihara S, Funahashi T, Matsuzawa Y, Libby P. Adiponectin: key adipocytokine in metabolic syndrome. Clinical Science (London) 2006; 110:267-278.

Yuan J, Liu W, Liu ZL, Li N. cDNA cloning, genomic structure, chromosomal mapping and expression analysis of ADIPOQ (adiponectin) in chicken. Cytogenetic and Genome Research 2006;112:148-151. 